\title{
SUPERFICIAL PERIPHERAL VEIN TYPE CLASSIFICATION OF ADOLESCENTS, ADULTS AND ELDERLY ACCORDING TO THE DELPHI TECHNIQUE
}

\author{
Cristina Arreguy-Sena ${ }^{1}$ \\ Emilia Campos de Carvalho ${ }^{2}$
}

Arreguy-Sena C, Carvalho EC. Superficial peripheral vein type classification of adolescents, adults and elderly according to the Delphi technique. Rev Latino-am Enfermagem 2008 janeiro-fevereiro; 16(1):86-94.

This descriptive research attempts to cooperate with the standardization of communication about vein types in Nursing. Authors utilized the "Delphi" technique and aimed at elaborating and validating a peripheral vein type classification of adolescents/adults/elderly according to their vein characteristics. Initially, authors identified different vein types in literature. This was a preliminary classification that contained the titles and definitions, which were complemented during the expert (nurses, angiologists, anesthetists and biochemists) validation process. Twelve criteria and 27 vein types were validated (agreement level $\geq 90 \%$ ). In addition, authors organized a set of pictures representing the different vein types. From these, 144 were used; 35 experts chose one picture to exemplify each classification title. The pictures representing 21 vein types were identified. This classification contributes to the clinical assessment of blood vessels and can be used in teaching, research and patient care management.

DESCRIPTORS: veins; classification; adolescent; adult; aged

\section{CLASIFICACIÓN DE LAS VENAS PERIFÉRICAS SUPERFICIALES EN ADOLESCENTES, ADULTOS Y ANCIANOS MEDIANTE LA TÉCNICA DELPHI}

Esta investigación descriptiva tiene por objetivo colaborar en la estandarización de los tipos de venas para la práctica de enfermería. Se utilizó la técnica "Delphi", para elaborar y validar una clasificación sobre los tipos de venas periféricas superficiales en adolescentes/adultos/ancianos, para ello se tuvo en consideración las características de los vasos. Inicialmente se identificó a través de la bibliografía los diferentes tipos de venas, los cuales conformaron la clasificación, usando títulos y definiciones que fueron complementados durante el proceso de validación por expertos (enfermeros, angiólogos, anestesiólogos y bioquímicos). Se validaron 12 criterios y 27 tipos de venas (nivel de concordancia $\geq 90 \%$ ). Además, se elaboró un conjunto de fotos representativas para la población sobre los diferentes tipos de venas, de las cuales fueron usadas 144. De esta forma, 35 peritos escogieron una foto como ejemplo de cada título de clasificación, siendo identificadas las fotos representativas de 21 tipos de venas. Esta clasificación contribuyó en la evaluación clínica de los vasos sanguíneos, pudiendo ser utilizada para la enseñanza, investigación y gestión en el cuidado del paciente.

DESCRIPTORES: venas; classificación; adolescente; adulto; anciano

\section{CLASSIFICAÇÃO DE VEIAS SUPERFICIAIS PERIFÉRICAS DE ADOLESCENTES, ADULTOS E IDOSOS PELA TÉCNICA DELPHI}

Esta pesquisa descritiva visa colaborar com a padronização da comunicação sobre os tipos de veias na prática de enfermagem. Utilizou a técnica "Delphi" e teve como objetivo elaborar e validar uma classificação sobre os tipos de veias superficiais periféricas de adolescentes/adultos/idosos, segundo características dos vasos. Inicialmente foram identificados pelos autores na literatura os diferentes tipos de veias, que constituíram a classificação, contendo títulos e definições que foram complementadas durante o processo de validação por peritos (enfermeiros, angiologistas, anestesistas e bioquímicos). Foram validados 12 critérios e 27 tipos de veias (ind. concordância $\geq 90 \%$ ). Complementarmente foi constituído um conjunto de fotos, representacional na população, dos diferentes tipos de veias. Destas, 144 foram usadas; 35 peritos escolheram uma foto para exemplificar cada título da classificação. Foram identificadas fotos representativas de 21 tipos de veia. Esta classificação contribui para a avaliação clínica do vaso sanguíneo, podendo ser empregada no ensino, na pesquisa e na gestão do cuidado ao paciente.

DESCRITORES: veias; classificação; adolescente; adulto; idoso

${ }^{1}$ RN, PhD, Assistant Professor at Juiz de Fora Federal University, Brazil, e-mail: cristina.arreguy@ufjf.edu.br; ${ }^{2}$ RN, PhD, Professor at University of São Paulo at Ribeirão Preto College of Nursing - WHO Collaborating Centre for Nursing Research Development, Brazil, e-mail: ecdcava@usp.br 


\section{INTRODUCTION}

The historical evolution of the materials used for peripheral and/or central vein punctures is an example of the rapid changes occurred in the health sector, including the introduction of metallic needles ${ }^{(1)}$; the impact of the disinfection process of reusable needles; the use of grindstones to whet or polish needles until the 1980's, in order to minimize the trauma the roomba needles could cause to people's muscles and blood vessels; and the emergence of the Aids pandemic, which created a new paradigm about the self and heteroprotection when dealing with biological materials and reinforced the need for the adoption of disposable needles in health praxis ${ }^{(2-4)}$. It should be added that improvements in work legislation and the increasing value the health workforce adds to society also reinforced the replacement of traditional activities (such as needle whetting, gauze folding, among others) by new industrialized hospital products. However, despite technological progress, there are possibilities of damage to the vein network during diagnosis, care and hemodynamic assessment $^{(5-7)}$

Thus, professionals with good puncture skills still may face challenges, especially considering the wide range of characteristics and conditions of clients' blood vessels. Equally, they may observe great difficulty to name the vein types. Therefore, they tended to use knowledge about the anatomic nomenclature and evidence originated from the morbid state(s) to name them. In this context, nurses established a special communication process; a new language that incorporated specific designations for the veins that can be punctured. Sometimes, in group communication, a new designation can be observed, such as "challenging vein" for example.

Communication studies, including the use and validation of nursing taxonomies, encouraged them to elaborate and to validate a vein type classification. The process of developing and using a classification is not new to the profession; these classifications contribute to the establishment of a common language, providing comparable data or defining a precise denomination for a fact or event, whether in teaching, research or care.

A classification needs to reflect its purpose, its conceptual domain; it needs to be logical, clear, relevant and useful. This process involves continuous development and refinement ${ }^{(8-9)}$. Hence, this study is relevant to enable an agreement about peripheral puncture vein types through language standardization among nursing professionals.

\section{OBJECTIVE}

Elaborate and validate a classification containing a title, a definition and picture examples about vein types.

\section{METHODOLOGY}

This descriptive study utilized the Delphi technique ${ }^{(10)}$. The research project was approved at the UFJF Hospital Research Ethics Committee. It was divided in two phases: 1) elaboration and validation of a peripheral puncture vein type classification; 2) assignment of a picture representing the vein type listed in the classification.

In order to accomplish the first task, a group of experts or judges evaluated the vein type nomenclature and classification titles. The following criteria were used for expert selection: 1) professional category with a university degree, with practical experience in peripheral blood vessels puncture for diagnosis, hemodynamic or therapeutic ends, such as nurses, angiologysts, anesthetists, biochemists; 2) the selection of a representative of each professional category was based on the time of experience in teaching and/or research on blood vessel puncture, the number of blood vessel puncture activities performed, knowledge on the area and/or considering peers recognition, as well as development of professional activities in health institutions in the South and Southeast regions of the country and 3) a minimum sample of 16 experts $^{(11)}$, so as to assure the same or a higher number of specialists when compared to the possibilities for the five levels that constituted the Likert scale we used. Therefore, the sample consisted of 35 participants: 14 nurses, seven angiologists, seven anesthetists and seven biochemists. A 90\% agreement level was adopted for this phase to guarantee reliability. In the preliminary version, the instrument presented the different types of designations for the veins (definitions and titles), formatted according to a fivepoint Likert scale ${ }^{(11-16)}$ ( 1 = completely irrelevant/ inadequate; 2 = moderately irrelevant/inadequate; 3 = relevance/adequacy level similar to irrelevance/ 
inadequacy level; $4=$ moderately relevant/adequate and 5 = completely relevant/adequate). Relevance and adequacy were used as synonyms. The answers were collected using statistical criteria. When experts did not agree with the questions, their comments guided subsequent discussions, with a view to: a) 1) offer new elements for a new declaration and/or a new title; 2) present the question for the experts' discussion and suggestions; 3) find out about individual opinions and 4) analyze the possibility/need to include new criteria. These discussions were accompanied by new approaches or led to the end of the questions, when the expected level of agreement was obtained. This cycle was repeated until they reached an agreement with respect to all the diverging questions.

The preliminary content version of the classification that was submitted to the experts' analysis was a result of the authors' previous experience from clinical evidences about the blood vessels that were localized in the client's superior members which they had the opportunity to see, handle or evaluate, seeking to make it compatible with a possible title and definition that are adequate to the specificities of each situation. The classifications were built according to a synergy structure for the titles and declarations approach and according to distinct and excluding criteria for elements of a same criterion, being modified and expanded in accordance with the emergent demand from the experts' opinion. Some pre-requisites were used as standardization/ reference strategies for the following criteria: width; visibility; location having the joint as a reference; location having the anatomic structure as a reference. The nomenclature based on anatomy (Nomina Anatomica) resulted from Latin and is considered official at international level and highly mentioned in text books, anatomy atlas as well as periodicals. It should be added to the classification elaborated in this research. In order to describe the blood vessels "width" classification criterion, we sought to approximate the blood vessel width to the intravascular device itself, in which the rigid or flexible needle devices were considered by means of ABNT (Brazilian Association of Technical Norms) measurement references. This institution is responsible for the equalization of these devices in Brazil ${ }^{(17)}$. For the visibility criterion, we adopted the inspection concepts, that is, resources characterized by a body structure, systemized and identified by vision, while equipped inspection referred to the use of any material in the observation process. As the term articulation refers to the connection between bone structures, an articulation concept that was based on the external body structure was elaborated and standardized according to the participants' suggestions. Next, they were incorporated into the text. The criteria and types of veins that were validated were:

Criterion: Mobility

1) Mobile vein - it is the vein that presents position mobility or variation, no matter if it is in the whole trajectory or in part of it. As a result, this type of vein shows instability because it glides on deep plans and adjoining areas when one tries to puncture it; 2) Steady vein - it is the vein that presents mobility or tendency to remain in the same position, no matter if it is in its whole trajectory or in part of it, presenting position stability because of the support of adjoining deep and/or anatomy structures when one tries to puncture it; 3) Vein that cannot be classified for the proposed criterion - it is the vein that cannot be classified according to the mobility criterion.

Criterion: Trajectory

1) Straight vein - it is the vein that presents a trajectory that goes in the straight direction in the whole or in part of its course, being perceived visually or through touch as regular; 2) Tortuous vein - it is the vein that presents a sinuous or bent trajectory, no matter if it is in the whole or in part of its trajectory, being perceived visually or through touch as irregular; 3) Vein that cannot be classified for the proposed criterion - it is the vein that cannot be classified according to the trajectory criterion.

Criterion: Insertion/Derivation

1) Oblique communicant vein is located between the others, such as two vein drainage territories. Its derivation or insertion angle is sharp in one extremity and obtuse in the other; 2) Horizontal Communicant Vein is located between other two, such as two superficial vein drainage territories. Its insertion or derivation angle is straight in both extremities; 3 ) Vein that cannot be classified for the proposed criterion - it is the vein that cannot be classified according to the insertion/derivation criterion. 
Criterion: Width

1) Small width vein - adolescent/adult/ elderly veins whose external layer (adventitious) width is superior or close to the external width of number $27 G$ (specify) or $25 \mathrm{G}$ (specify) scalp or similar to the correspondent width of other intravenous devices, and its installation makes the internal layer (intimate) vessel width compatible with the mentioned width, without causing vein expansion; 2) Medium width vein adolescent/adult/elderly veins whose external layer (adventitious) width is superior or close to the width of a number $21 \mathrm{G}$ (specify) or 23G (specify) scalp or similar to the correspondent widths of other intravenous devices, and its installation makes the internal layer (intimate) vessel width compatible with the mentioned width, without causing vein expansion; 3) Large width vein - adolescent/adult/elderly veins whose external layer (adventitious) width is superior to the width of a number $19 \mathrm{G}$ (specify) scalp or similar to the correspondent widths of other intravenous devices, and its installation makes the internal layer (intimate) vessel width compatible with the mentioned width, without causing vein expansion; 4) Vein that cannot be classified for the proposed criterion - it is the vein that cannot be classified according to the width criterion.

\section{Criterion: Visibility}

1) Visible vein is easily visualized, whether because of its large or expressive width, because of the trajectory's superficiality or because of its bluish or greenish color observed through non equipped inspection;

2) Vein of difficult visualization is difficult to visualize during non equipped inspection, whether because of its insignificant wall width (definitive or temporary), its deepened insertion between other anatomy structures or the absence of a different color visualization in its trajectory; 3) Vein that cannot be classified for the proposed criterion - it is the vein that, during non equipped or equipped inspection (for example, when the body structure tourniquet is employed), shows an impossible visualization, no matter whether because of its insignificant wall width (definitive or temporary), deepened insertion in other anatomy structures or the absence of different colors in its trajectory.

Criterion: Palpability

1) Palpable vein - it is the vein that, when inspected, appears to be engorged, visible and/or prominent, and easily identified through palpation; 2) Non palpable vein - it is the vein that during an inspection does not seem to be engorged and is difficult to perceive through touch; 3) Vein that cannot be classified for the proposed criterion - it is the vein that cannot be classified according to the palpability criterion.

Criterion: Location with reference to the joint

1) Vein located in the joint - it is the vein located in the superior limb joint (ginglymus, ellipsoid and simple), i.e., in the region between the $10 \%$ space of the value of the circumference of the articulation structure, proximally or distally when we take the line of the joint flexion analyzed as a reference; 2) Vein located out of the joint - it is the vein located out of the superior limb joint, i.e., out of the region between the $10 \%$ space of the value of the circumference of the articulation structure, proximally or distally when we take the line of the joint flexion as a reference; 3 ) Vein that cannot be classified for the proposed criterion - it is the vein that cannot be classified according to the location with reference to the joint criterion.

Criterion: Location with reference to the anatomy structure

1) Arm's vein - it is the vein located in the superior right or left arm, in the anterior, medium or lateral member's face (veins: axillary, basilic, cephalic, its derivations or anatomy variations); 2) Forearm's vein - it is the vein located in the right or left superior forearm member, in the anterior, medium or lateral's member's face (veins: basilic, intermediate basilic, cephalic, intermediate cephalic, intermediate brachial, radial, ulnar), its derivations or anatomy variations; 3) Hand's vein - it is the vein located in the right or in the left hand in the dorsal face (superficial arch palm vein, its derivations or its anatomy variations); 4) Finger's vein - it is the located in the index finger phalanx on the right or on the left in the dorsal, medium or lateral (lateral and medium superficial fingers veins), its derivations or anatomy variations; 5) Vein that cannot be classified for the proposed criterion - it is the vein that cannot be classified according to the location with reference to the anatomy structure criterion. 
Criterion: Width regularity of the vein trajectory

\section{1) Regular or homogenous trajectory}

width vein - it is the vein that presents integer and non expanded valves, as the regularity appearance and width constancy (without stenosis areas in the vein trajectory) have been detected during the inspection and touch; 2) Vein with irregular trajectory width of the valve or nodded type it is the vein that presents small phlebectasias or dilatations located in the valves insertion, causing, during the insertion and the palpation, some irregularities in the vessel width and resulting in the appearance of some nodes in the vein trajectory. 3 ) Vein that cannot be classified for the proposed criterion - it is the vein that cannot be classified according to the location with reference to the anatomy structure and the international nomenclature criterion.

Criterion: The vein trajectory elasticity

\section{1) Hardened consistency trajectory}

vein - it is the vein that, when palpated, presents some circumscribed areas with lessened elasticity and distension, giving to the person who is performing this procedure the sensation of palpating a consistent and hardened structure (that appears to be a cord); 2) Flexible consistency trajectory vein - it is the vein that, when palpated, keeps its elasticity and distension properties, giving the person who is performing this procedure the sensation of flexibility and softness of the vessel walls; 3 ) Vein that cannot be classified for the proposed criterion - it is the vein that cannot be classified according to the consistency of the vein trajectory.

Criterion: Continuity Solution of the Vessel Walls

1) Vein with blood vessel walls continuity solution - it is the vein that presents circumscribed discontinuity of all vessel layers. They are presented with some ruptures, which are caused by accidents (traumas, strokes), pathological situations (coagulation disturbs), the use of the indicated or self determined medicine and/or its undesirable effects (punctures, transfixions). When inspected and measured, evidences appear of content extravasation and the site where the device needle was inserted can be identified; 2) Vein without blood vessel walls continuity solution - it is the vein that does not present discontinuity in its walls. They do not have ruptures caused by accidents (traumas, strokes) or the use of indicated or self determined medicine and/or its undesirable effects (punctures, transfixions). Thus, they do not present inspection, palpation or measurement detectable evidences of content extravasation, nor is it possible to identify a likely intravenous insertion place in its trajectory; 3) Vein that cannot be classified for the proposed criterion - it is the vein that cannot be classified according to the continuity solution of the vessel walls criterion.

Criterion: Puncture Easiness

1) Easily punctured vein - it is the straight, steady vein, of large or medium width, which is palpable and homogenous, with a flexible consistency trajectory, without continuity solution. According to the characteristics, this propitiates the vein puncture process; 2) Difficultly punctured vein - it is the mobile and tortuous vein, of small width, which is difficult or impossible to visualize and non palpable. It presents nods and hardened vein trajectory, with continuity solution and, according to the vein characteristics, this makes the vein puncture process difficult; 3) Vein that cannot be classified for the proposed criterion - it is the vein that cannot be classified according to the puncture possibility criterion.

Criterion: Other criteria to be included

The agreement levels obtained in the validation are described in the results section.

In the second stage, a picture representing each vein type was identified, although the photographic resource is- according to the methodological point of view- incompatible with criteria that could be understood through the use of a semiotic non-visual technique, which constitutes a restriction of the present study. Initially, a set of pictures of the different adolescents', adults' and elderly persons' forearm and hand peripheral vein types was arranged. In 
order to take the pictures, we selected a sample with six representatives of each race, both male and female and living in the states of Minas Gerais, Paraná and São Paulo (Brazil). The pictures were standardized according to participants' age group, position in which the pictures were taken (frontal or lateral camera position), environment temperature when pictures were taken $\left(30^{\circ} \mathrm{C}\right.$ to $38^{\circ} \mathrm{C}$ or $86^{\circ} \mathrm{F}$ to $100.4^{\circ} \mathrm{F}$ ), tourniquet use in the photographed body structure or not, presence of a numeric rank that allowed to dimension the picture size in relation to the body structure and inclusion of different races and male and female participants. Eight photos of each participant were taken. Nine of them were outpatients and belonged to three races, totaling 216 photos. Photos of three of the participants of each race were excluded, because of a lack of age group compatibility, although authors adopted a 2-year variation (above or under) in the participant age group. This study considered 144 photos. Afterwards, at least one photo identifying each vein type and representing the adopted criteria was selected. Four expert nurses were responsible for the preliminary trial; two of them were academics and the other two clinicians, and all of them had more than ten years of professional experience in teaching and/or care. Three photos of each sample were made available to three experts, who selected the number of photos for each title which they considered appropriate. Next, they worked together to reduce their size. The fourth expert excluded one of the three photos. Thus, only two photos were presented to the participants of the first stage. Therefore, the agreement level presented in table 1 about the picture selection refers to the choice of the best picture from two images that had previously been considered representative of the criterion.

\section{RESULTS AND DATA ANALYSIS}

The 35 experts who elaborated and validated the vein type classification had different backgrounds and professions. Seven of them were male anesthetics, 32 to 50 years old, and their professional experience varied from two to 28 years. All of them had medical residence and a specialist title in the area. The other seven experts were angiologists and, because this is a new specialization, some vascular surgeons were included among the experts of this professional category. All of them were male, who had done their medical residences and had a specialist title, with ages ranging from 34 to 70 years (five of them were 43 to 58 years old), and professional experience varying from 2 to 40 years; among the seven biochemists, five were men and two women, with ages varying from 30 to 58 years, five of them had completed their medical residences and two of them possessed only the university degree, and work experience in the area varied from 7 to 30 years. Among the nurses, there were 13 women and one man. Their ages varied from 35 to 58 years, and their work experience from 13 to 25 years, showing an early start of their professional career. Among the nurses, three of them had a Doctoral degree, seven a Master's degree, three were specialists and one of them an Undergraduate degree. All participants were involved with peripheral blood vessel assessment and/or handling.

This study resulted in a classification about the superficial vein types of adolescent, adult and/ or elderly, composed of 12 different criteria (mobility, trajectory, insertion/derivation, width, visibility, palpability, location with reference to the joint, location with reference to the anatomic structure, width regularity of the vein trajectory; vein trajectory elasticity, continuity solution of the vessel walls, puncture easiness). The agreement index about the titles and declarations among the experts can be analyzed in four groups, such as: A) criteria that obtained unanimous agreement among experts for titles and declarations simultaneously; B) criteria that obtained unanimous title concordance among experts and declaration concordance superior to $90 \%$ : C) criteria that obtained unanimous declaration concordance among experts and title concordance superior to $90 \%$; D) criteria that obtained concordance within the adopted score level, but inferior to $100 \%$ among experts both for title and declaration. The vein types called "cannot be classified for any of the proposed criteria" were unanimously considered as such on all criteria; the levels obtained by the other categories are presented in Table 1. 
Table 1 - Agreement level obtained in criteria validation, vein types and selection of pictures to classify peripheral veins

\begin{tabular}{|c|c|c|c|}
\hline \multirow{2}{*}{ Criterion } & \multirow{2}{*}{ Vein type } & \multicolumn{2}{|c|}{ Agreement level } \\
\hline & & Titles and statements & Picture selection \\
\hline \multirow[t]{2}{*}{ Mobility } & Mobile Vein & Title $>90 \%$ and Statement $=100 \%$ & $91.42 \%$ \\
\hline & Steady vein & Title $>90 \%$ and Statement $=100 \%$ & $82.86 \%$ \\
\hline \multirow[t]{2}{*}{ Trajectory } & Straight vein & Title $>90 \%$ and Statement $=100 \%$ & $100 \%$ \\
\hline & Tortuous vein & Title $>90 \%$ and Statement $=100 \%$ & $100 \%$ \\
\hline \multirow[t]{2}{*}{ Insertion / Derivation } & Oblique communicant vein & Title and Statement $>90 \%$ & $100 \%$ \\
\hline & Horizontal communicant vein & Title and Statement $>90 \%$ & $100 \%$ \\
\hline \multirow[t]{3}{*}{ Width } & Small width vein & Title $=100 \%$ Statement $>90 \%$ & $100 \%$ \\
\hline & Medium width vein & Title $=100 \%$ Statement $>90 \%$ & $97 \%$ \\
\hline & Large width vein & Title $=100 \%$ Statement $>90 \%$ & $100 \%$ \\
\hline \multirow[t]{2}{*}{ Visibility } & Visible vein & Title and Statement $=100 \%$ & $97.14 \%$ \\
\hline & Vein of difficult visualization & Title and Statement $=100 \%$ & $85.71 \%$ \\
\hline \multirow[t]{2}{*}{ Palpability } & Palpable vein & Title and Statement $=100 \%$ & $82.86 \%$ \\
\hline & Non palpable vein & Title and Statement $=100 \%$ & Not classified \\
\hline \multirow[t]{2}{*}{ Puncture Easiness } & Easily punctured vein & Title and Statement $>90 \%$ & 97.14 \\
\hline & Difficultly punctured vein & Title and Statement $>90 \%$ & 100 \\
\hline \multirow[t]{2}{*}{ Location with reference to the joint } & Vein located in the joint & Title $=100 \%$ Statement $>90 \%$ & $51.43 \%$ \\
\hline & Vein located out of the joint & Title $=100 \%$ Statement $>90 \%$ & $85.71 \%$ \\
\hline \multirow{4}{*}{$\begin{array}{l}\text { Location with reference to the anatomic } \\
\text { structure }\end{array}$} & Arm's vein & Title $=100 \%$ Statement $>90 \%$ & Not classified \\
\hline & Forearm's vein & Title $=100 \%$ Statement $>90 \%$ & $100 \%$ \\
\hline & Hand's vein & Title $=100 \%$ Statement $>90 \%$ & $100 \%$ \\
\hline & Finger's vein & Title $=100 \%$ Statement $>90 \%$ & $88.56 \%$ \\
\hline \multirow[t]{2}{*}{ Width regularity of the vein trajectory } & Regular or homogenous trajectory width vein & Title and Statement $=100 \%$ & $100 \%$ \\
\hline & $\begin{array}{l}\text { Vein of irregular trajectory width of the valve or } \\
\text { nodded type }\end{array}$ & Title and Statement $=100 \%$ & 51.43 \\
\hline \multirow[t]{2}{*}{ The vein trajectory elasticity } & Hardened consistency trajectory vein & Title and Statement $=100 \%$ & Not classified \\
\hline & Flexible consistency trajectory vein & Title and Statement $=100 \%$ & Not classified \\
\hline \multirow[t]{2}{*}{ Continuity solution of the vessel walls } & Vein with blood vessel walls continuity solution & Title and Statement $=100 \%$ & Not classified \\
\hline & Vein without blood vessel walls continuity solution & and Statement $=100 \%$ & Not classified \\
\hline
\end{tabular}

The 144 color photos were analyzed by experts, who preserved two good examples of photos for a better selection. All pictures that obtained the major part should correspond to the title for which they were selected. This fact was confirmed by the comments of more than $95 \%$ of the 35 experts who participated in the first work stage, since they stated that all pictures they had seen were excellent. The experts' concordance index for the best pair of available photos was distributed like this: 1) unanimity; 2) $97,14 \%$; 3) $91,42 \%$; 4) $88,56 \%$; 5) $85,71 \%$; 6) $82,86 \%$; 7) $51,43 \%$. Figures 1 to 4 show black and white pictures of these situations. It is also important to consider that the experts have plural labor practice for the use of the vein network according to the developed/evolved action point of view or its use purpose. Due to this fact, some items have obtained differentiated assessment with evaluation and agreement.

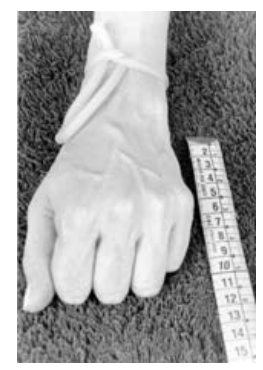

1 - Mobile Vein

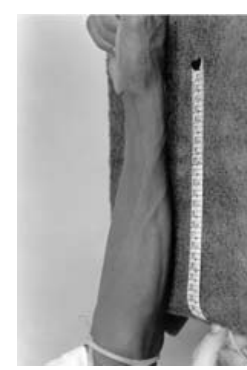

2 - Steady Vein

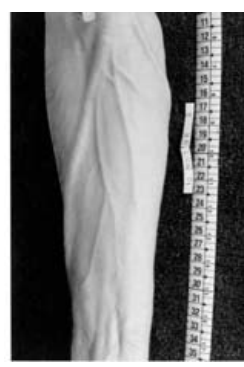

3 - Straight Vein

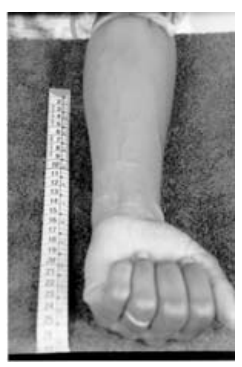

4 - Tortuous Vein

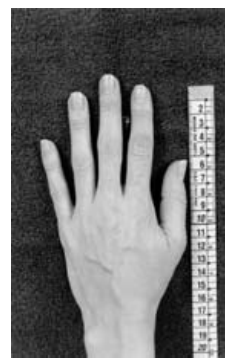

5 - Oblique Communicant Vein

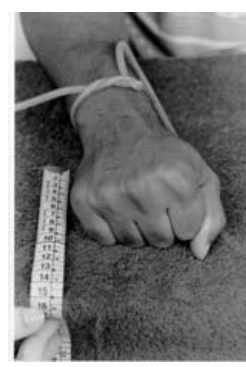

6 - Horizontal Communicant Vein

Figure 1 - Vein types. Examples of vein pictures classified according to the Mobility $(1,2)$, Trajectory $(3,4)$ and Insertion / Derivation $(5,6)$ criteria 


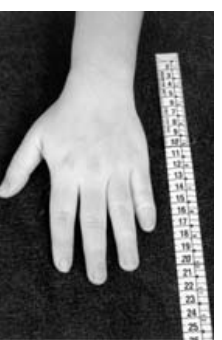

5 - Vein of Difficult Visualization

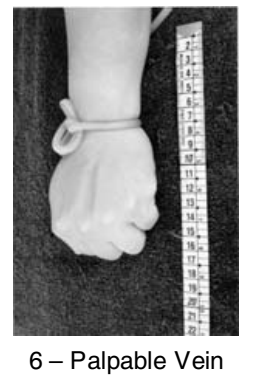

6 - Palpable Vein
1 - Small Width Vein Vein

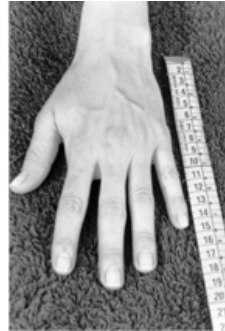

4 - Visible Vein

Figure 2 - Vein types. Examples of vein pictures classified according to the Width $(1,2,3)$; Visibility (4,5) Palpability (6)

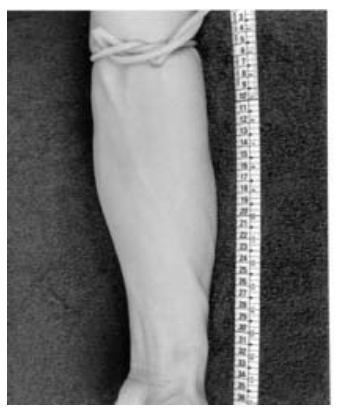

1 - Forearm's vein

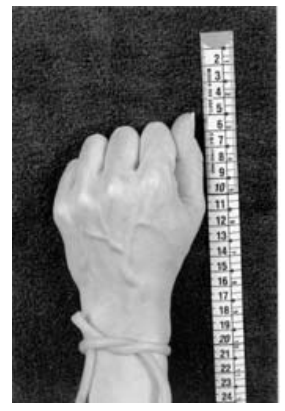

2 - Hand's vein

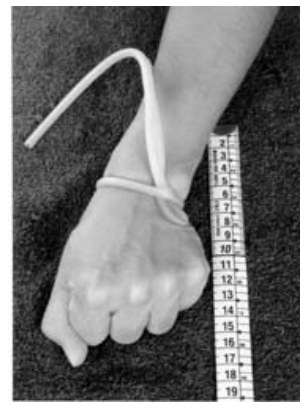

3 - Finger's vein

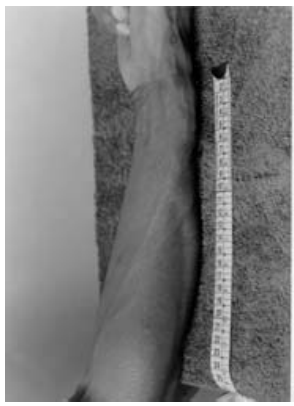

4 - Easily punctured vein

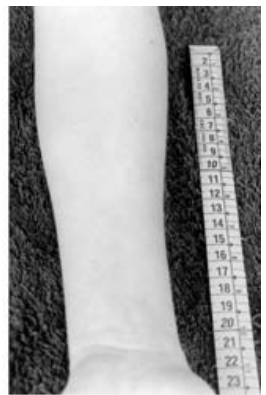

5 - Difficultly punctured vein

Figure 3 - Vein types. Examples of vein pictures classified according to the criteria: Location with reference to the anatomy structure $(1,2,3)$; Puncture Easiness $(4,5)$

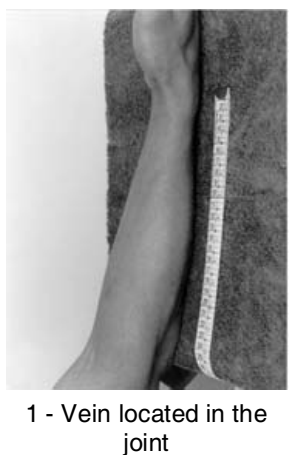

joint

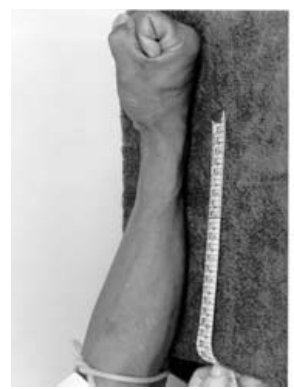

2 - Vein located out of the joint

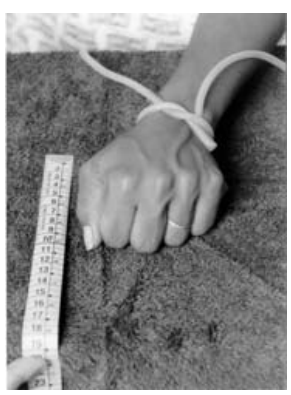

3 - Regular or homogenous trajectory width vein

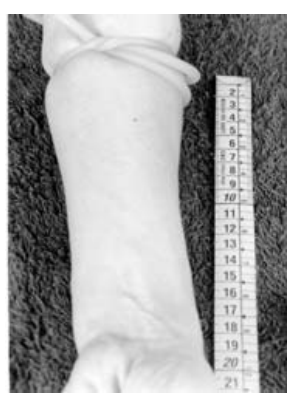

4 - Vein of irregular trajectory width of the valve or nodded type

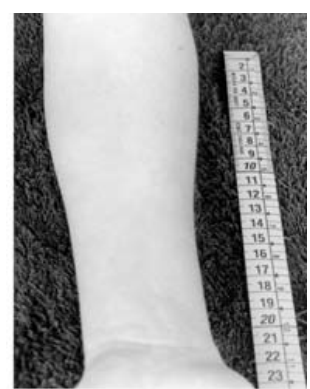

5 - Vein that cannot be classified for the proposed criterion

Figure 4 - Vein types. Examples of vein pictures classified according to the criteria: Location with reference to the joint $(1,2)$; Width regularity of the vein trajectory $(3,4)$ and cannot be classified for any of the proposed criteria (5)

With respect to the process of choosing the set of pictures to represent the different vein types, it is important to emphasize that some titles could not be exemplified, given the methodological trajectory, which used visual assessment to select the pictures: 1) "hardened consistency trajectory vein" and "flexible consistency trajectory vein", which belong to the "vein trajectory elasticity" criterion; 2) "non palpable vein", included in the palpability criterion;

For other titles, pictures could not be validated either, due to the population selection criteria: "vein without blood vessel walls continuity solution" and "vein with blood vessel walls continuity solution", included in the "continuity solution of the vessel walls" criterion. These vein conditions are usually observed in hospitalized persons, after multiple punctures. However, according to the selection criteria, all photographed subjects were healthy and possessed intact veins.

Finally, one other title could not be exemplified either, as pictures in this study represented forearm and hand structures, so that no examples were found 
for this criterion. This was the case for "arm's vein", included in the "location with reference to the anatomic structure" $^{(11)}$ criterion.

Despite the construction and validation of this classification, including the types and criteria described above, this study is limited by the lack of picture examples for the above mentioned titles. However, the description of these veins contributes to their naming / labeling in clinical practice.

\section{FINAL CONSIDERATIONS}

The classification of adolescents, adults and elderly persons' superficial peripheral vein types developed in this research is composed of 12 consensus criteria (agreement level of more than $90 \%$ for completely adequate/relevant and not inferior to $10 \%$ for moderately adequate/relevant): mobility, trajectory, insertion/derivation, width, visibility, palpability, location with reference to the joint, location with reference to the anatomy structure, width regularity of the vein trajectory, the vein trajectory elasticity continuity solution of the vessel walls and puncture easiness; the "other criterion to be included" was equally approved. This aspect adds to the

\section{REFERENCES}

1. Meyers L. Intravenous catheterization. Am J Nurs 1945; 45(2):930-1.

2. Maeda ST. Escalpe, equipo de soro e seringa descartável: critérios qualitativos para subsidiar a compra. [dissertação]. São Paulo (SP): Escola de Enfermagem/USP; 1998.

3. Arreguy-Sena C. A relação entre o preconceito social e o comportamento de infectados pelo HIV numa instituição hospitalar, segundo a percepção desses. [dissertação] Rio de Janeiro (RJ): EEAN/UFRJ; 1991.

4. Ministério da Saúde (BR). Manual de normas técnicas para prevenção da transmissão da AIDS. Brasília (DF): Ministério da Saúde, 1989.

5. Arreguy-Sena C. A trajetória de construção e validação dos diagnósticos de enfermagem: Trauma vascular e risco para trauma vascular. [Tese ] Ribeirão Preto (SP): EERP/USP; 2002. 6. Lastória S. Tromboflebite superficial. In: Maffei FHA, Lastória S, Yoshida WB, Rollo HA. Doenças vasculares periféricas. $2^{a}$ ed. São Paulo (SP): MEDSI; 1995, p.831-40. 7. Phillips LD. Manual de terapia intravenosa. $2^{a}$ ed. Porto Alegre (RGS): Artmed; 2001.

8. Clark KJ. How nurses can participate in the development of. an ICNP. Int Nurs Rev 1996 November-December; 43(6):171-4. consideration that a classification should foresee the inclusion of new terms or their refinement.

The consensus among the 35 experts concerning the titles and declaration concordance index of each criterion was facilitated by the use of the Delphi technique. In order to measure the participants' opinion, the use of a Likert scale in all stages favored an agreement on the evaluation parameter. When participants chose the pictures, they had already accomplished a title and declaration approximation about what each photo should represent.

First, four experts selected the pictures, avoiding exhaustive meetings with all 35 participants and facilitating the operational conduction of this stage. Pictures exemplifying 21 titles were obtained and the other titles could not be exemplified through photos, because of the incompatibility of the visual criterion with the variables defined in this work. However, other pictures can be added, considering the criterion "location with reference to the anatomy structure" for example. The classification, in spite of being simple, covers a diversity of criteria through which a vein can be analyzed. Some experts manifested the utility of this classification for undergraduate teaching, research on the theme and professional recycling on vein puncture, either verbally or in writing.

9. Nielsen $\mathrm{GH}$, Mortensen RA. The architecture for an international classification for nursing practice (ICNP). Int Nurs Rev 1996 November-December; 43(6):175-82.

10. Lindeman CA. Delphi survey of priorities in clinical nursing research. Nurs Res 1975; 24(6):434-41.

11. Duffield C. The Delphi Techinique: a comparison of results obtained using two expert panels. Lut J Nurs Stud. 1993; 30: 277-37.

12. Faro ACM Técnica Delphi na Validação das intervenções de Enfermagem. Rev Esc Enfermagem USP 1997 agosto; 31(1):259-73.

13. Guilford JP. Psychometric methods. Bombay (EUA): Mc Graw Hill; 1971.

14. Rodrigues A. Psicologia Social. Petrópolis (RJ): Vozes; 1993. 15. Procter $S$, Hunt M. Using the Delphi survey technique to develop a professional definition of nursing for analysing nursing workload. J Adv Nurs 1994; 19:1003-14.

16. Salmond SW. Orthopaedic nursing research priorities: a Delphi study. Orthop Nurs 1994; (2):31-45.

17. Associação Brasileira de Normas Técnicas - ABNT. NBR 9753. Escalpe estéril e de uso único: requisitos e métodos de ensaio. Rio de Janeiro (RJ): ABNT: abril 1997. 